Pacific Journal of Mathematics

DIFFERENTIABLE POWER-ASSOCIATIVE GROUPOIDS 


\title{
DIFFERENTIABLE POWER-ASSOCIATIVE GROUPOIDS
}

\author{
JOHN P. HOLMES
}

\begin{abstract}
Suppose $H$ is a Banach space, $D$ is an open set of $H$ containing 0 , and $V$ is a function from $D \times D$ to $H$ satisfying $V(0, x)=V(x, 0)=x$ for each $x$ in $D$. If $n$ is an integer greater than 1 , denote by $x^{n}$ the product of $n-x$ 's associated as follows whenever the product exists.
\end{abstract}

$$
x^{n}=V(x, V(x, \cdots V(x, x) \cdots)) .
$$

Define $x^{0}=0$ and $x^{1}=x . \quad V$ is said to be power associative if and only if $V\left(x^{n}, x^{m}\right)=x^{n+m}$ whenever each of $n$ and $m$ is a nonnegative integer and $x^{n+m}$ exists.

Theorem A. If $H$ and $V$ are as above, $V$ is power associative and continuously differentiable in the sense of Frechet on $D \times D$ then there are positive numbers $a$ and $c$ such that if $x$ is in $H$ and $\|x\|<a$ there is a unique continuous function $T_{x}$ from $[0,1]$ to the ball of radius $c$ centered at 0 satisfying $V\left(T_{x}(s), T_{x}(t)\right)=T_{x}(s+t)$ whenever each of $s, t$, and $s+t$ is in $[0,1], T_{x}(0)=0$, and $T_{x}(1)=x$.

Theorem $A$ is similar to a result in [1] of Birkhoff. He showed that if $H$ and $V$ are as above, $V$ is associative, $V$ is Frechet differentiable on a neighborhood of $(0,0)$, and $V^{\prime}$ is continuous at $(0,0)$ then some neighborhood of 0 is covered by partial homomorphic images of the additive group of real numbers.

To see that Theorem A is not a special case of this result of Birkhoff, we offer the following example. Denote by $E$ the 2-dimensional Euclidean space and define $V$ from $E \times E$ to $E$ by $V((x, y),(z$, $w))=(x+[1+(x w-y z)] z, y+[1+(x w-y z)] w)$. If $S$ is a 1-dimensional linear subspace of $E$ and each of $p$ and $q$ is in $S$ then $V(p, q)=$ $p+q$. Thus $V$ is power associative and 0 is an identity for $V$. $V$ is not associative but $V$ is continuously differentiable on $E \times E$.

We will now prove Theorem A. Regard $H \times H$ as a Banach space in the usual way, defining the norm of a member $(x, y)$ of $H \times H$ by $\|(x, y)\|=\max \{\|x\|,\|y\|\}$. If $c$ is a positive number, denote by $R(c)$ the set to which $x$ belongs if and only if $x$ is in $H$ and $\|x\|<c$. Finally, if $B$ is a bounded linear transformation from $H \times H$ to $H$ or from $H$ to $H$, denote the norm of $B$ by $|B|$.

Define $f$ from $D$ to $H$ by $f(x)=V(x, x)=x^{2}$ for each $x$ in $D$. Note $f$ is continuously differentiable on $D$ and if $x$ is in $D, f^{\prime}(x)(y)=$ $V^{\prime}(x, x)(y, y)$ for each $y$ in $H$. Moreover, $V^{\prime}(0,0)(z, w)=z+w$ for each pair $(z, w)$ in $H \times H$ so $f^{\prime}(0)=2 I$ where $I$ is the identity transfor- 
mation on $H$.

Employing the inverse function theorem (for instance [2] page 268) we see that there is a positive number $b$ and an open set $U$ of $H$ such that $(f \mid U)$ is a homeomorphism of $U$ onto $R(b)$ and $g=(f \mid U)^{-1}$ is continuously differentiable on $R(b)$ with $g^{\prime}(y)=\left[f^{\prime}(g(y))\right]^{-1}$ for each $y$ in $R(b)$. Hence $g^{\prime}(0)=1 / 2 I$.

By continuity of $g^{\prime}$ and $V^{\prime}$ there is a positive number $d$ and a number $M$ such that if $p$ is in $R(d) \times R(d)$ and $x$ is in $R(d)$ then $\left|V^{\prime}(p)\right|<M$ and $\left|g^{\prime}(x)\right|<2 / 3$.

Suppose each of $x, y, z$, and $w$ is in $R(d)$. Then $\| V(x, y)-V(z$, $w)\|=\| \int_{0}^{1} d t V^{\prime}((z, w)+t(x-z, y-w))(x-z, y-w)\|<M\|(x-z$, $y-w) \|$. As special cases of this inequality we obtain

$$
\begin{aligned}
& \text { 1. }\|V(x, y)\|<M\|(x, y)\| \text { and } \\
& \text { 2. }\|V(x, y)-y\|<M\|x\| \text {. }
\end{aligned}
$$

Similarly, if each of $x$ and $y$ is in $R(d)$ we have $\|g(x)-g(y)\|=\| \int_{0}^{1}$ $d t g^{\prime}(y+t(x-y))(x-y)\|<2 / 3\| x-y \|$. Hence $g$ is Lipschitz on $R(d)$ and has Lipschitz norm less than 2/3. In particular, for each $x$ in $R(d)$ and each positive integer $m$ we have $\left\|g^{m}(x)\right\|<(2 / 3)^{m}\|x\|$ where $g^{m}$ is $g$ composed with itself $m$ times.

Lemma 1. Let $r=d / 3 M$. If $x$ is in $R(r), m$ is a positive integer, and $n$ is an integer in $\left[0,2^{m}\right]$ then $\left[g^{m}(x)\right]^{n}$ exists and has norm less than $M\|x\| \sum_{1}^{m}(2 / 3)^{i}$.

Proof. Note $\left|V^{\prime}(0,0)\right|=2$ so $M>3 / 2$. If $x$ is in $R(r)$, it is clear, using inequality 1 , that $g^{1}(x)^{i}$ exists for each $i=0,1$, or 2 and has norm less than $M\|x\|(2 / 3)$.

Suppose $m$ is an integer greater than 1 and assume that for each integer $k$ in $[1, m)$ that $g^{k}(x)^{s}$ exists for each integer $s$ in $\left[0,2^{k}\right]$ and has norm less than $M\|x\| \sum_{1}^{k}(2 / 3)^{i}$.

As has been observed before, $g^{m}(x)$ exists and $\left\|g^{m}(x)^{0}\right\|=0$. Suppose $n$ is an integer in $\left(0,2^{m}\right]$ and assume for each integer $c$ in $[0, n)$ that $g^{m}(x)^{c}$ exists and has norm less than $M\|x\| \sum_{1}^{m}(2 / 3)^{i}$.

Then $g^{m}(x)^{n-1}$ exists and $\left\|g^{m}(x)^{n-1}\right\|<M\|x\| \sum_{1}^{m}(2 / 3)^{i}<2 M\|x\|<$ $2 M r=2 M d / 3 M<d$. Thus $g^{m}(x)^{n-1}$ is in $D$ and $g^{m}(x)^{n}=V\left(g^{m}(x), g^{m}(x)^{n-1}\right)$ exists.

If $n$ is even, we may use power associativity and the equality $g^{m}(x)^{2}=g^{m-1}(x)$ to obtain $g^{m}(x)^{n}=g^{m-1}(x)^{n / 2}$. Hence, by the first inductive hypothesis, $\left\|g^{m}(x)^{n}\right\|<M\|x\| \sum_{1}^{m}(2 \mid 3)_{i}$.

If $n$ is odd then $g^{m}(x)^{n}=V\left(g^{m}(x), g^{(m-1)}(x)^{(n-1) / 2}\right)$. Using the triangle 
inequality, inequality 2 , and the first inductive hypothesis we obtain $\left\|g^{m}(x)^{n}\right\| \leqq\left\|V\left(g^{m}(x), g^{m-1}(x)^{(n-1) / 2}\right)-g^{m-1}(x)^{(n-1)}\right\|+\left\|g^{m-1}(x)^{(n-1) / 2}\right\|<$ $M\|x\| \sum_{1}^{m}(2 / 3)^{i}$.

Thus we have Lemma 1.

Suppose $x$ is in $R(r)$. Denote by $E$ the set of dyadic rational numbers in [0,1] and define $T$ from $E$ to $H$ by $T\left(n / 2^{m}\right)=g^{m}(x)^{n}$. $\quad T$ exists by Lemma 1 and is well defined by power associativity. Moreover, by power associativity, $V(T(h), T(k))=T(h+k)$ whenever each of $h, k$, and $h+k$ is in $E$. Lemma 2 will show that $T$ has a continuous extension to all of $[0,1]$.

Lemma 2. If $x$ and $T$ are as above, each of $h$ and $k$ is in $E$, and $|h-k|<1 / 2^{m}$ for some positive integer $m$ then $\|T(h)-T(k)\|<$ $9 M\|x\|(2 / 3)^{m+1}$.

Proof. Suppose $h=s / 2^{m+n}$ for some nonnegative integers $s$ and $n$, and $u$ is an integer with each of $u / 2^{m}$ and $(u+1) / 2^{m}$ in $E$ so that $h$ is in $\left[u / 2^{m},(u+1) / 2^{m}\right]$. There is a sequence $a_{1}, \cdots, a_{n}$ such that $h=u / 2^{m}+a_{1} / 2^{m+1}+\cdots+a_{n} / 2^{m+n}$ and each $a_{i}$ is in the set $\{0,1\}$. Thus $T(h)=V\left(T\left(u / 2^{m}\right), V\left(T\left(a_{1} / 2^{m+1}\right), \cdots, V\left(T\left(a_{n-1} / 2^{m+n-1}\right), T\left(a_{n} /\right.\right.\right.\right.$ $\left.\left.2^{m+n}\right)\right) \cdots(\cdot)$.

Let $w$ be defined from $\{0,1, \cdots, n\}$ by $w_{i}=u / 2^{m}+\sum_{1}^{i} a_{j} / 2^{m+j}$. Then $w_{i}=w_{i-1}+a_{i} / 2^{m+i}$ for each $i$ in $\{1, \cdots, n\}$. Now, using the triangle inequality, we have $\left\|T(h)-T\left(u / 2^{m}\right)\right\| \leqq \sum_{1}^{n}\left\|T\left(w_{i}\right)-T\left(w_{i-1}\right)\right\| \cdot$ But, using inequality 2 we obtain $\left\|T\left(w_{i}\right)-T\left(w_{i-1}\right)\right\| \leqq M\left\|T\left(a_{i} / 2^{m+i}\right)\right\|<$ $M\|x\|(2 / 3)^{m+i} . \quad$ Hence $\quad\left\|T(h)-T\left(u / 2^{m}\right)\right\|<M\|x\| \sum_{1}^{m}(2 / 3)^{m+i}<$ $3 M\|x\|(2 / 3)^{m+1}$.

There is an integer $u$ such that each of $(u-1) / 2^{m}$ and $(u+1) / 2^{m}$ is in $E$ and each of $h$ and $k$ is in $\left[(u-1) / 2^{m},(u+1) / 2^{m}\right]$. Hence, by using the triangle inequality and the inequality just proved, we obtain Lemma 2.

From Lemma 2 it is clear that $T$ has a continuous extension to all of $[0,1]$. If each of $s, t$, and $s+t$ is in $[0,1]$, choose sequences $\left\{a_{n}\right\}_{1}^{\infty}$ and $\left\{b_{n}\right\}_{1}^{\infty}$ in $E$ converging to $s$ and $t$ respectively so that for each positive integer $n, d_{n}=a_{n}+b_{n}$ is in $E$. By continuity of $V$ and $T$, we have $V(T(s), T(t))=\lim _{n} V\left(T\left(a_{n}\right), T\left(b_{n}\right)\right)=\lim _{n} T\left(d_{n}\right)=$ $T(s+t)$.

Choose $c$ positive and less than $r$ so that $R(c)$ is contained in $g(R(d))$. Let $a=c / 3 M$. If $x$ is in $R(a)$ then, by Lemma $1, T_{x}$ maps into $R(c)$. Suppose $F$ satisfies the conclusion of theorem $A$ for $x$ in $R(a)$. $F(1 / 2)$ is in $R(c)$ and hence in $g(R(d)) . \quad F(1 / 2)^{2}=x$ and $x$ is in $R(d)$ so $g(x)=F(1 / 2)$. Similarly $g^{m}(x)=F\left(1 / 2^{m}\right)$ for each positive integer $m$, and hence $F$ agrees with $T_{x}$ on $E$. Since each of $F$ and $T_{x}$ is continuous, the proof is complete. 


\section{REFERENCES}

1. Garrett Birkhoff, Analytical groups, Trans. Amer. Math. Soc., 43 (1938), 61-101.

2. J. Dieudonne, Foundations of Modern Analysis, New York and London: Academic Press, 1960.

Received August 9, 1971 and in revised form December 20, 1971. This research was supported in part by an NDEA Title IV Graduate Fellowship.

\section{EMORY UNIVERSITY}

AND

UNIVERSITY OF FLORIDA 


\section{PACIFIC JOURNAL OF MATHEMATICS}

\section{EDITORS}

\author{
H. SAMELSON \\ Stanford University \\ Stanford, California 94305

\section{R. HoвBY} \\ University of Washington \\ Seattle, Washington 98105
}

\section{J. DugundJI}

Department of Mathematics University of Southern California Los Angeles, California 90007

\author{
RichaRd ARENS \\ University of California \\ Los Angeles, California 90024
}

\section{ASSOCIATE EDITORS}
E. F. BECKENBACH
B. H. NEUMANN
F. WOLF
K. YoshidA

\section{SUPPORTING INSTITUTIONS}

\author{
UNIVERSITY OF BRITISH COLUMBIA \\ CALIFORNIA INSTITUTE OF TECHNOLOGY \\ UNIVERSITY OF CALIFORNIA \\ MONTANA STATE UNIVERSITY \\ UNIVERSITY OF NEVADA \\ NEW MEXICO STATE UNIVERSITY \\ OREGON STATE UNIVERSITY \\ UNIVERSITY OF OREGON \\ OSAKA UNIVERSITY
}

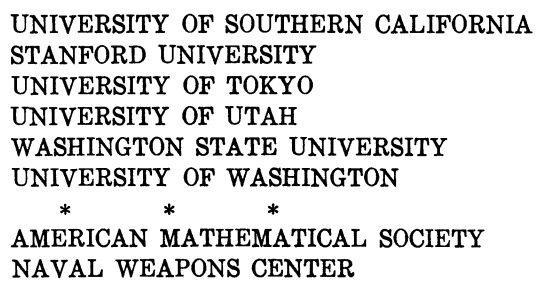

The Supporting Institutions listed above contribute to the cost of publication of this Journal, but they are not owners or publishers and have no responsibility for its content or policies.

Mathematical papers intended for publication in the Pacific Journal of Mathematics should be in typed form or offset-reproduced, (not dittoed), double spaced with large margins. Underline Greek letters in red, German in green, and script in blue. The first paragraph or two must be capable of being used separately as a synopsis of the entire paper. The editorial "we" must not be used in the synopsis, and items of the bibliography should not be cited there unless absolutely necessary, in which case they must be identified by author and Journal, rather than by item number. Manuscripts, in dup icate if possible, may be sent to any one of the four editors. Please classify according to the scheme of Math. Rev. Index to Vol. 39. All other communications to the editors should be addressed to the managing editor, Richard Arens, University of California, Los Angeles, California, 90024.

50 reprints are provided free for each article; additional copies may be obtained at cost in multiples of 50 .

The Pacific Journal of Mathematics is published monthly. Effective with Volume 16 the price per volume (3 numbers) is $\$ 8.00$; single issues, $\$ 3.00$. Special price for current issues to individual faculty members of supporting institutions and to individual members of the American Mathematical Society: $\$ 4.00$ per volume; single issues $\$ 1.50$. Back numbers are available.

Subscriptions, orders for back numbers, and changes of address should be sent to Pacific Journal of Mathematics, 103 Highland Boulevard, Berkeley, California, 94708.

PUBLISHED BY PACIFIC JOURNAL OF MATHEMATICS, A NON-PROFIT CORPORATION

Printed at Kokusai Bunken Insatsusha (International Academic Printing Co., Ltd.), 270, 3-chome Totsuka-cho, Shinjuku-ku, Tokyo 160, Japan. 


\section{Pacific Journal of Mathematics}

\section{Vol. 41, No. 2 December, 1972}

Tom M. (Mike) Apostol, Arithmetical properties of generalized Ramanujan sums .......................................... 281

David Lee Armacost and William Louis Armacost, On p-thetic groups ........ 295

Janet E. Mills, Regular semigroups which are extensions of groups .......... 303

Gregory Frank Bachelis, Homomorphisms of Banach algebras with minimal ideals ................................................ 307

John Allen Beachy, A generalization of injectivity .................. 313

David Geoffrey Cantor, On arithmetic properties of the Taylor series of rational functions. II.........................................

Václáv Chvátal and Frank Harary, Generalized Ramsey theory for graphs. III.

Small off-diagonal numbers .................................. 335

Frank Rimi DeMeyer, Irreducible characters and solvability of finite groups . . . . 347

Robert P. Dickinson, On right zero unions of commutative semigroups........ 355

John Dustin Donald, Non-openness and non-equidimensionality in algebraic

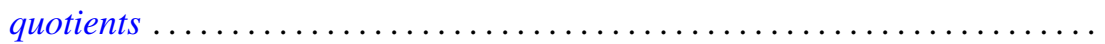

John D. Donaldson and Qazi Ibadur Rahman, Inequalities for polynomials with a prescribed zero ........................................ 375

Robert E. Hall, The translational hull of an $N$-semigroup ................ 379

John P. Holmes, Differentiable power-associative groupoids.............. 391

Steven Kenyon Ingram, Continuous dependence on parameters and boundary data for nonlinear two-point boundary value problems .

Robert Clarke James, Super-reflexive spaces with bases ..........

Gary Douglas Jones, The embedding of homeomorphisms of the plane in

continuous flows...............................

Mary Joel Jordan, Period $H$-semigroups and $t$-semisimple periodic

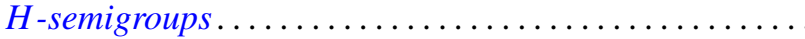

Ronald Allen Knight, Dynamical systems of characteristic 0

Kwangil Koh, On a representation of a strongly harmonic ring by sheaves...

Hui-Hsiung Kuo, Stochastic integrals in abstract Wiener space. ..

Thomas Graham McLaughlin, Supersimple sets and the problem of extending a

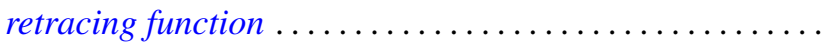

William Nathan, Open mappings on 2-manifolds .

M. J. O'Malley, Isomorphic power series rings

Sean B. O'Reilly, Completely adequate neighborhood systems and metrization

Qazi Ibadur Rahman, On the zeros of a polynomial and its derivative...

Russell Daniel Rupp, Jr., The Weierstrass excess function ..

Hugo Teufel, A note on second order differential inequalities and functional

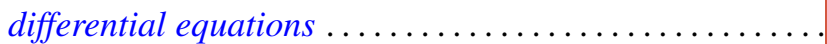

M. J. Wicks, A general solution of binary homogeneous equations over free 